\title{
Selenium Nutritional Status of Rural Residents and Its Correlation with Dietary Intake Patterns in a Typical Low-Selenium Area in China
}

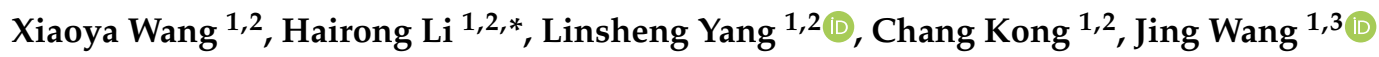 \\ and Yingchun $\mathrm{Li}^{4}$ \\ 1 Key Laboratory of Land Surface Pattern and Simulation, Institute of Geographical Sciences and Natural \\ Resources Research, Chinese Academy of Sciences, Beijing 100101, China; wangxy.17s@igsnrr.ac.cn (X.W.); \\ yangls@igsnrr.ac.cn (L.Y.); kongc.15s@igsnrr.ac.cn (C.K.); jingwang@ccnu.edu.cn (J.W.) \\ 2 College of Resources and Environment, University of Chinese Academy of Sciences, Beijing 100101, China \\ 3 Key Laboratory for Geographical Process Analysis \& Simulation, Research Institute of Sustainable \\ Development, Central China Normal University, Wuhan 430079, China \\ 4 Centre for Disease Prevention and Control of Binxian County, Xianyang 713500, China; \\ liyingchun1353@gmail.com \\ * Correspondence: lihr@igsnrr.ac.cn; Tel.: +86-010-648-891-98
}

Received: 1 November 2020; Accepted: 9 December 2020; Published: 13 December 2020

\begin{abstract}
China is recognized as a selenium-deficient country, and nutritional selenium intake has always been a concern. To clarify the current inhabitants' selenium nutrition status and the characteristics of dietary consumption in low-selenium areas, samples of human hair and grains were collected, and food frequency questionnaires were administered in Binxian County, Shaanxi Province, a typical low-selenium area in the Loess Plateau. The subject number of the study is 85 , and the age range is from 11 to 81 years, with an average of 60 . The results showed that the average hair selenium content of the residents was $231.7 \mu \mathrm{g} / \mathrm{kg}$, and $62.4 \%$ of the participants had levels higher than the selenium deficiency threshold $(200 \mu \mathrm{g} / \mathrm{kg})$. There was a significant positive correlation between the hair selenium content and the food consumption score after adjusting for rice outsourcing. Three different dietary patterns were noted according to hierarchical cluster analysis. This study provides a tool for assessing the selenium nutrition of inhabitants in low-selenium areas and has considerable significance for improving the dietary pattern of residents.
\end{abstract}

Keywords: Binxian; low-selenium area; hair; food consumption frequency; hierarchical; correlation

\section{Introduction}

Selenium is an essential micronutrient for humans [1]. This micronutrient plays an important role in redox homeostasis, antioxidant defense and the immune system via selenoenzymes and selenoproteins [2]. However, selenium intake is insufficient in many countries. There are $0.5-1$ billion people are affected by selenium deficiency in the world [3]. China is one of 40 selenium-deficient countries reported by the World Health Organization (WHO) [4], for there is a low selenium belt in China. The formation of a low selenium belt is determined by the migration characteristics and biological characteristics of selenium in the environment. Low selenium in the soil is the basis of its formation. A low-selenium environment leads to insufficient selenium intake through the food chain [5], which causes serious health consequences, such as Keshan disease and Kashin-Beck disease (KBD) [6-8]. KBD mainly occurs in children aged 5-13 years. The clinical manifestations of it are rheumatoid arthritis, shortening of fingers and toes, thickening of joints or growth disorders of 
organisms [3]. The geographical distribution of KBD coincides with the severe selenium deficiency belt from northeast to southwest China [9].

Since the 1980s, various comprehensive measures were taken to prevent and control Keshan disease and KBD, in addition, the socio-economic status was continuous developed and the living conditions has improvement in China, the selenium nutrition of the population has obviously increased in the low-selenium areas of China. Many KBD-affected areas have reached the national control standard, but the progression varies greatly [10]. There is still a large gap between daily selenium intake and selenium physiological nutrition requirements in rural residents living in low-selenium belt areas [11]. As diet is the crucial determinant of daily selenium intake, it is necessary to conduct a study on selenium nutrition status, dietary selenium intake pathways and daily selenium intake amount to explore the effect of the evolution of food consumption characteristics on the changes in selenium nutrition among residents in typical low-selenium belt areas.

The hair selenium content is a commonly used index for evaluating human selenium nutrition as it was found that selenium levels measured in human hair have a good correction with those in kidney, liver, lung, plasma [12,13], and blood [14]. Hair selenium can be sensitive to selenium intake and in vivo selenium levels over a period of time $[15,16]$; therefore, hair is usually used in epidemiological studies to assess the long-term selenium nutritional status of the population, particularly for those with stable dietary habits $[17,18]$.

To assess residents' intake of selenium from various foods, a food frequency questionnaire (FFQ) and 3-day weighed food record (WFR) were administered. Previous studies have proven that the results of the FFQ have no significant difference from those of the WFR in assessing dietary energy and nutrient intake $[19,20]$. The FFQ focuses on the overall dietary structure and can reflect nutrient intake patterns [21,22], and it is of guiding significance for dietary improvements. However, due to the large variation in soil selenium, the selenium intake from crops in different regions differs greatly. Therefore, the food composition table is not suitable for estimating selenium intake, which should be instead of the actual value of selenium in local crops [2].

Binxian County, located in mid-western Shaanxi Province on the south of the Loess Plateau in China, had overt deficiencies in selenium nutrition levels and a serious KBD prevalence in the 1980s [23]. The child incidence of KBD was $43.33 \%$, and the average hair selenium content of the population was only $140 \mu \mathrm{g} / \mathrm{kg}$ at that time [24,25]. Previous studies showed that the dietary structure of the population of Binxian County was unbalanced in the 1980s, the main staple food of the residents was local self-grown wheat; there was a greater consumption of pickles than of stir-fry; and the consumption of meat, milk, eggs and fruit was very low. With economic development and a series of measures to prevent and control KBD [10,26], residents' living standards have been improving gradually, selenium nutrition has also improved to a certain extent, and the risk of KBD in Binxian County has been greatly reduced. However, there has been no systematic assessment of whether the effects of a low-selenium environment have been removed to date or of the relationship of these effects with changes in the food consumption structure of rural residents.

In this study, Binxian County was selected as a typical study area in which to explore the following two questions: (1) Does the current nutrition status of selenium meet the physiological selenium requirement for rural inhabitants in a typical low-selenium area? (2) What are the dietary habits of the inhabitants, and what is the comprehensive relationship between selenium nutriton levels and food consumption characteristics? This work provides a scientific basis for proposing relevant nutrition strategies and guiding the improvement of selenium nutrition in residents living in selenium-deficient areas. 


\section{Materials and Methods}

\subsection{Materials Sampling and Pretreatment}

The study protocol was approved by the Center for Disease Prevention and Control of Binxian County and the agreement of the village clinics. All individuals gave their informed consent for inclusion before they participated in the survey. According to the distribution of KBD endemic areas in Binxian County and the terrain features of this area, 11 villages were selected as the sample sites. Hair samples from 5-10 villagers were collected with stainless steel scissors, and grain samples were also collected. Additionally, a food frequency questionnaire was administered in each selected village. Rice samples were obtained from a local market. Ultimately, we obtained 85 hair samples from 42 men and 43 women with an average age of 60 years, including 38 people diagnosed with KBD according to the clinical diagnostic criteria and 47 people without KBD. We obtained 66 valid questionnaires, 66 wheat samples and 4 rice samples. Figure 1 presents the sampling sites in Binxian County.

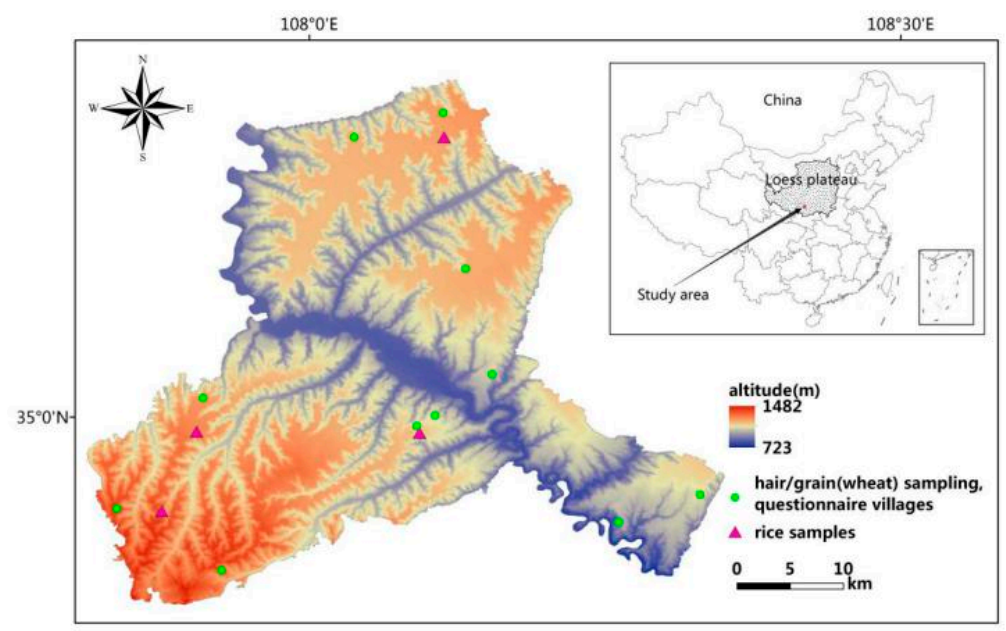

Figure 1. Distribution of sampling sites.

Hair samples of no less than $2 \mathrm{~g}$ were collected from pillows and placed in a clean glass beaker, soaked in a specific proportion of neutral detergent solution for $24 \mathrm{~h}$, stirred several times with a glass rod during immersion, and then successively washed with tap water, distilled water and ultra-pure water. The hair was then heated at $60^{\circ} \mathrm{C}$ for approximately $4 \mathrm{~h}$ in an oven. Then, the dried hair was cut into approximately 5-mm pieces with ceramic scissors and stored for analysis.

The non-powdered grains were successively washed with tap water, distilled water and ultra-pure water, dried at a low-temperature (not higher than $60^{\circ} \mathrm{C}$ ) in an oven, crushed in a stainless steel mill (FW-100, Taisite Instrument Co., Ltd., Tianjin, China) and then bagged for use [27]. The flour was immediately bagged for use.

\subsection{Calculation Methods}

The food questionnaire examined the rural residents' frequency of consumption of various foods in the past month. According to the statistical yearbook data for Shaanxi Province, the consumption of aquatic products by rural residents in Shaanxi Province was only 1.0 kg/year in 2017 [28], which had little impact on selenium intake. Moreover, the food consumption frequency pre-investigation indicated that local residents rarely ate aquatic products; hence, the consumption of aquatic products was not considered. All foods were divided into eight items, namely: grains, potatoes, beans, eggs, meats, milk, vegetables and fruits, on the basis of the Food Guide Pagoda for Chinese residents. The daily consumption frequency score for each food item was calculated using the method shown in Table 1. The frequency scores for each item were added to yield the total food consumption frequency score (FFQS). The formula is shown below as Formula (1). 
FFQS (food frequency questionnaire score) $=\sum_{i=1}^{i=8}$ frequency score

Table 1. Categories of consumption frequency [29].

\begin{tabular}{ccc}
\hline Score & Category & Definition \\
\hline 1 & $\geq 1 /$ day & Once/more than once a day \\
0.7 & $4-6 * /$ week & $4-6$ times a week \\
0.3 & $1-3 * /$ week & $1-3$ times a week \\
0.1 & $2-3 * /$ month & $2-3$ times a month \\
0.03 & $1 * /$ month & Once a month \\
0 & $0 /$ rarely & Never/hardly ever \\
\hline & $*$ =times (i.e.,: 4 */week $=4$ times/week).
\end{tabular}

The second step was to consider the effect of exogenous foods. In addition to the relatively large amount of local wheat, outsourced rice was found to be an additional staple food for some residents in the study area. The selenium content of the outsourced rice was obviously higher than that of the local wheat grown in the low-selenium environment [30]. The calculation divided the selenium content of the rice by the selenium content of the wheat and then multiplied the resulting value by the rice frequency score. This accounted for the extra intake of selenium from rice consumption compared to that of wheat consumption. The obtained value was included in the grain score in the second step. The following Formula (2) shows the calculation method:

$$
\text { FFQS }=\sum_{i=1}\left(1+\frac{\text { rice selenium content }}{\text { wheat selenium content }}\right) \times \text { frequency score }+\sum_{i=2}^{i=8} \text { frequency score }
$$

The third step was to evaluate the residents' daily selenium intake amount. This method multiplied the adjusted score in step 2 by the selenium content and consumption amount of all 8 food items. The selenium content data for each item except for grains were derived from the literature, the Chinese Food Composition Tables (Standard Edition) and The Fifth China Total Diet Study [30-32]. The consumption data were obtained from the Food Guide Pagoda from the dietary guidelines for Chinese residents [33]. The median interval value of the recommended intake per food item was used. Table 2 contains the details for these data. An individual daily selenium intake amount was calculated using Formula (3):

$S I A$ (selenium intake amount $)(\mu \mathrm{g} / \mathrm{d})=\sum_{i=1} F F Q S^{\prime} \times$ wheat selenium content $\times$ consumption $+\sum_{i=2}^{i=8} F F Q S^{\prime} \times$ selenium content of food item $\times$ consumption

Table 2. Selenium content and consumption data.

\begin{tabular}{ccccc}
\hline Item & $\begin{array}{c}\text { Selenium } \\
\text { Content }(\boldsymbol{\mu g} / \mathbf{k g})\end{array}$ & $\begin{array}{c}\text { Consumption } \\
\text { Recommended in the } \\
\text { Food Guide Pagoda (g) }\end{array}$ & $\begin{array}{c}\text { Consumption } \\
\text { Used in This } \\
\text { Study }(g)\end{array}$ & Sources \\
\hline Grains & $\begin{array}{c}\text { Results of this } \\
\text { study }\end{array}$ & $250-400$ & 325 & $/$ \\
Potatoes & 14.4 & $50-100$ & 75 & {$[32]$} \\
Beans & 48.8 & $25-30$ & 27.5 & {$[30]$} \\
Meats & 78 & $40-75$ & 60 & {$[32]$} \\
Milk & 39.1 & 300 & 300 & {$[30]$} \\
Eggs & 225.3 & $40-50$ & 45 & {$[30]$} \\
Vegetables & 4.8 & $300-500$ & 400 & {$[32]$} \\
Fruits & 1.62 & $200-350$ & 275 & {$[31]$} \\
\hline
\end{tabular}




\subsection{Chemical Analysis}

The determination of total Se referred to national standards for the determination of Se in foods (GB/T 5009.93-2003). Hair and grain samples were digested in a mixture of concentrated $\mathrm{HNO}_{3}$ and $\mathrm{H}_{2} \mathrm{O}_{2}(\mathrm{~V} 1: \mathrm{V} 2=2: 1)$ on a hot plate at below $170{ }^{\circ} \mathrm{C}$ until the solution became clear, and then the selenium content was determined by inductively coupled plasma mass spectrometry (ICP-MS) [34]. Quality control was carried out according to the national standard materials GBW 07601a (human hair), GBW 10010 (rice) and GBW 10011 (wheat) for composition analysis, and 10\% of the samples were analyzed repeatedly. All the chemical reagents used were guaranteed to be of analytical grade.

\subsection{Statistical Analysis}

Data processing and chart production were mainly performed using SPSS 19.0 and Microsoft Excel 2010. A $t$-test was used to compare the differences between participangs diagnosed with KBD and those who were not. The Kruskal-Wallis H test was used for multiple independent sample comparisons. The hierarchical cluster method was used to analyze the characteristics of the residents' diet. The Spearman correlation coefficient was applied in this study, and the difference was significant at the 0.05 level.

\section{Results}

\subsection{Selenium Content in Hair}

The average hair selenium content of the study area is shown in Figure 2. The results show that the average hair selenium content of the residents was $231.7 \mu \mathrm{g} / \mathrm{kg}$, which was higher than the threshold for selenium deficiency $(200 \mu \mathrm{g} / \mathrm{kg})$ in KBD endemic areas [35]. Compared with the hair selenium content of other areas in Shaanxi Province, inhabitants living in the study area had a lower hair selenium content than those of adjacent Linyou County $(370 \mu \mathrm{g} / \mathrm{kg})$ and Yongshou County $(400 \mu \mathrm{g} / \mathrm{kg})$ [36]. As a contrast, the average hair selenium content of Shaanxi Province was $290 \mu \mathrm{g} / \mathrm{kg}$, the same as Heilongjiang Province, while in Guangxi Province is $390 \mu \mathrm{g} / \mathrm{kg}$ [11]. There were 38 patients with KBD, and they exhibited an average hair selenium content of $223.6 \mu \mathrm{g} / \mathrm{kg}$, ranging from $66.3 \mu \mathrm{g} / \mathrm{kg}$ to $381.2 \mu \mathrm{g} / \mathrm{kg}$; the 47 healthy participants had an average hair selenium content of $238.3 \mu \mathrm{g} / \mathrm{kg}$, ranging from 63.9 to $648.5 \mu \mathrm{g} / \mathrm{kg}$, and there was no significant difference between the two groups $(t=0.878, p>0.05)$. Figure 2 shows that 32 participants had hair selenium content below $200 \mu \mathrm{g} / \mathrm{kg}$, which accounted for $37.6 \%$ of the total participants, and the number of patients in females is slightly higher than in males; 19 participants had selenium content between $200 \mu \mathrm{g} / \mathrm{kg}$ and $250 \mu \mathrm{g} / \mathrm{kg}$, accounting for $22.3 \%$ of the total; 33 participants had moderate hair selenium levels, accounting for $38.8 \%$ of the total participants; and 1 female participant had a selenium content higher than $500 \mu \mathrm{g} / \mathrm{kg}$.

\subsection{Correlation between Hair Selenium Content and Food Consumption Characteristics}

According to the calculated results, the FFQS ranged from 1.16 to 6.80 , and the coefficient of the correlation between the FFQS and hair selenium content was $0.250(p<0.05)$. The FFQS', which is the FFQS adjusted for the ratio of the selenium contents of rice and wheat, ranged from 1.30 to 6.85 , and the coefficient of its correlation with hair selenium content increased to $0.518(p<0.01)$. This showed a good correlation between the FFQS' and the hair selenium content. Figure 3 presents the scatter diagram for the FFQS, FFQS' and hair selenium content. As shown in Figure 3, after the initial FFQS was adjusted for the ratio of the selenium contents of rice and wheat, the correlation coefficient increased significantly and linearly. Therefore, the FFQS' was more suitable for the assessment of selenium nutrition in residents of low-selenium areas than the FFQS was. 


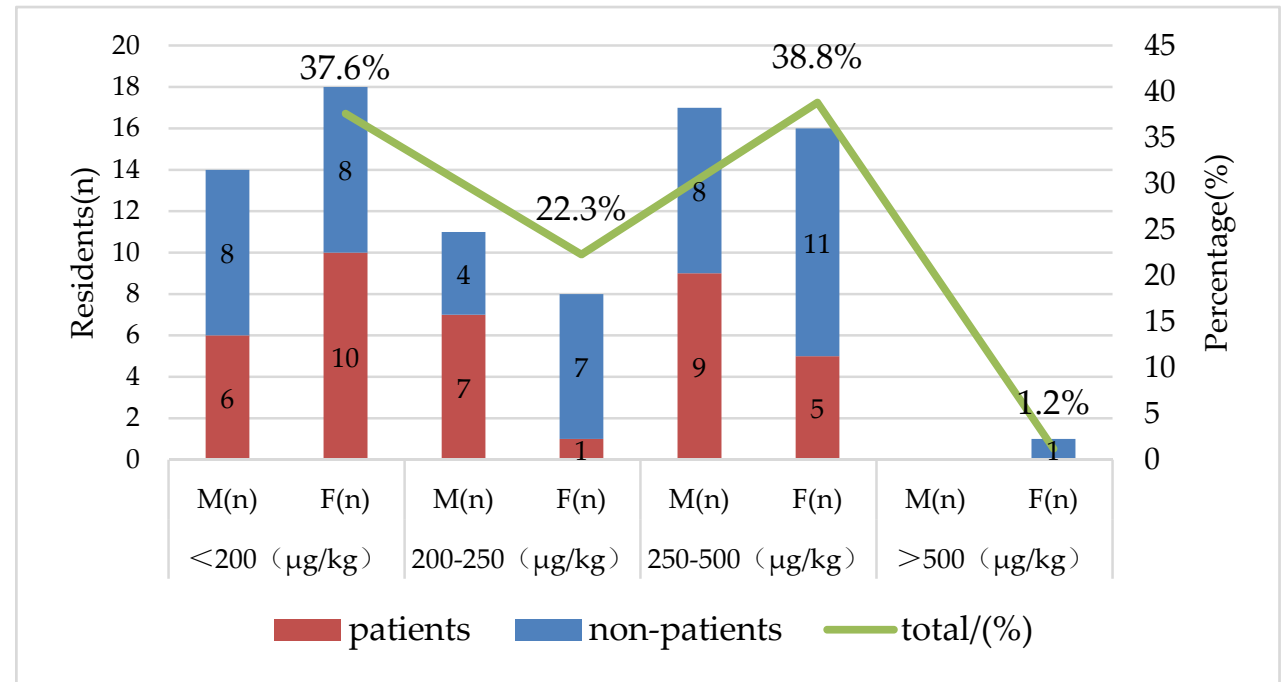

Figure 2. Distribution of hair selenium content in the study area (M: Male, F: Female, n: number).

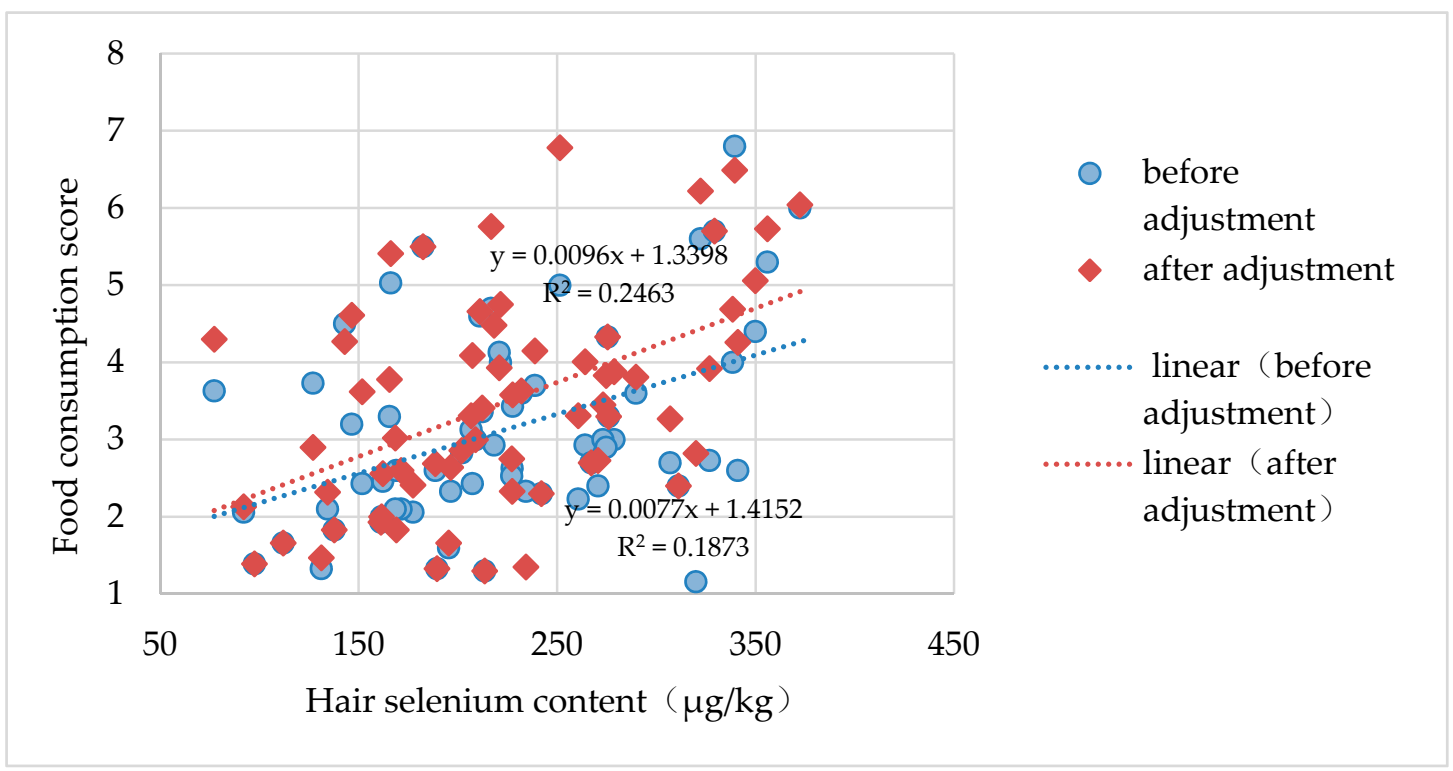

Figure 3. Scatter diagram of food consumption frequency score and hair selenium content $(\mu \mathrm{g} / \mathrm{kg})$.

Based on the recommended consumption of all kinds of foods in the Food Guide Pagoda for Chinese residents, the selenium content of local crops and other food selenium content data obtained from food composition tables, the residents' daily selenium intake amount (SIA) was determined to range from $5.10 \mu \mathrm{g} / \mathrm{d}$ to $41.32 \mu \mathrm{g} / \mathrm{d}$, and the coefficient of the correlation between SIA and the residents' hair selenium content was $0.190(p>0.05)$. This relatively low correlation coefficient shows that SIA is not a suitable method for evaluating individuals' daily selenium intake in a low-selenium area.

\subsection{Hierarchical Cluster Analysis of the FFQS'}

Based on the high correlation between FFQS' and hair selenium content, hierarchical cluster analysis was applied to the food consumption score (FFQS') calculated in step 2 for all 8 food items. Summarizing the food consumption score of these three clusters, the average score of the 8 items food is shown in Table 3. The average hair selenium content and the average FFQS' corresponding to the three clusters are outlined in Table 4. The average hair selenium content of cluster 1 was $200.19 \mu \mathrm{g} / \mathrm{kg}$; for cluster 2, it was $231.99 \mu \mathrm{g} / \mathrm{kg}$; and for cluster 3, it was $288.50 \mu \mathrm{g} / \mathrm{kg}$. There were significant 
differences in hair selenium content among the three clusters $\left(\chi^{2}=10.625, p<0.05\right)$. Moreover, clusters 1 and $3(t=-3.884, p<0.01)$ and clusters 2 and $3(t=-2.045, p<0.05)$ had significant differences in terms of hair selenium content. The corresponding average FFQS' of clusters 1, 2, and 3 was 2.72 , 4.12 and 5.90, respectively, and there were significant differences among the groups $(p<0.01)$.

Table 3. The average consumption score for all 8 food items.

\begin{tabular}{cccccccccc}
\hline Cluster & $\boldsymbol{n}$ & Grains $^{*}$ & Potatoes & Beans & Meats & Milk & Eggs & Vegetables & Fruits \\
\hline 1 & 35 & 1.30 & 0.16 & 0.09 & 0.05 & 0.01 & 0.24 & 0.74 & 0.13 \\
2 & 21 & 1.72 & 0.25 & 0.21 & 0.15 & 0.11 & 0.36 & 0.86 & 0.46 \\
3 & 10 & 1.52 & 0.59 & 0.42 & 0.57 & 0.28 & 0.83 & 0.94 & 0.77 \\
\hline \multicolumn{8}{c}{ Grains * after adjustment for rice and wheat. }
\end{tabular}

Table 4. The average hair selenium content and FFQS' of the three clusters.

\begin{tabular}{cccc}
\hline Cluster & $\boldsymbol{n}$ & $\begin{array}{c}\text { Hair Selenium Content } \\
(\boldsymbol{\mu} \mathbf{g} / \mathbf{k g}) \text { Mean } \pm \text { S.D. }\end{array}$ & FFQS' mean \pm S.D. \\
\hline 1 & 35 & $200.19 \pm 59.27^{\mathrm{a}}$ & $2.72 \pm 0.91^{\mathrm{a}}$ \\
2 & 21 & $231.99 \pm 69.49^{\mathrm{a}}$ & $4.12 \pm 0.50^{\mathrm{b}}$ \\
3 & 10 & $288.50 \pm 77.08^{\mathrm{b}}$ & $5.90 \pm 0.58^{\mathrm{c}}$ \\
\hline
\end{tabular}

Two rows in the same column with different letters indicate a significant difference, while those with the same letter indicate no significant difference.

Specifically, there were 35 participants in the first food consumption pattern group (cluster 1), accounting for $53.03 \%$ of the total. The average hair selenium content in cluster 1 corresponded to the threshold for selenium deficiency $(200 \mu \mathrm{g} / \mathrm{kg})$. Cluster 1 had the largest number of individuals, which reflected the main dietary habits of the local inhabitants with a limited intake of outsourced food, beans, meats, milk and fruits. This shows that there was a certain degree of dietary imbalance in the population, which is consistent with other studies in China [37]. In comparison, the residents in the second and third food consumption clusters (cluster 2, cluster 3) had relatively abundant diets, and their selenium nutrition content were also higher than those of the residents in cluster 1 . In particular, although the average consumption frequency score for grain* was slightly lower in cluster 3 than in cluster 2, the average consumption of the other daily food items was significantly higher in cluster 3 than in the other two clusters, and the hair selenium content was also exceeded the healthy threshold (hair selenium $\geq 250 \mu \mathrm{g} / \mathrm{kg}$ ).

\section{Discussion}

In China, the economy has developed rapidly, and the income of farmers has continued to grow since the reform and opening up. Therefore, the living standard of residents has improved significantly, and food diversity increased. With the comprehensive prevention and control measures such as returning farmland to forest and grassland, eating selenium-added salt, the selenium nutrition level of the residents was significantly improved. Thus, many KBD patients have reached the selenium deficiency threshold. The selenium content in the hair of $62.4 \%$ of the residents were higher than the selenium deficiency threshold $(200 \mu \mathrm{g} / \mathrm{kg})$ [23], and the selenium content in the hair of $38.8 \%$ of the population reached the moderate level of selenium nutrition. However, the overall level of selenium is still lower than that of neighboring counties. The study suggests that there is no significant difference in selenium nutrition levels among residents in the KBD-affected area, which may be because the selenium nutrition of residents is affected not only by the local low-selenium environment but also by dietary structure, family economic factors, etc.

Although the low-selenium environment still exists, the structure of the residents' diet is gradually changing. The residents' dependence on the local low-selenium environment was reduced by the consumption of outsourced rice with high selenium content. The residents' selenium nutrition status 
could be roughly evaluated based on the composition of local and imported staples and the ratio of the selenium contents of the two staple foods.

According to the hierarchical cluster analysis, it is not difficult to find that in addition to increasing the intake of outsourced staple foods with high selenium contents, the consumption of various kinds of food also appears to be particularly important to improve selenium nutrition. Filippini also found that selenium intake was closely related to the frequency of consumption of meat, grains, milk and dairy products in a population survey of communities in northern Italy [38]. Based on the data in this study, if the FFQS' of a resident reaches 4.12, people can be considered to no longer be selenium deficient. The FFQS' could provide a reference for evaluating the selenium nutrition level via daily diet patterns in residents and could provide an approximate range for the selenium health threshold. Although the daily intake of selenium could be accurately estimated by investigating the intake amount of all kinds of food and determining the selenium content of various foods, doing so would require considerable effort and time. The FFQS' established in this study can roughly estimate the selenium nutrition level of rural residents by obtaining the consumption frequency of all kinds of food and the ratio of the selenium contents of local staple foods to that of outsourced staple foods, which may have great significance for evaluating the dietary structure and selenium nutrition level in other low-selenium areas. However, a smaller sample size is a limiting factor in this study. In future studies, the sample size will be expanded in order to obtain more suitable methods.

\section{Conclusions}

In summary, although the hair selenium content of residents in Binxian County is no longer indicative of an overall selenium deficiency, some rural inhabitants are still on the verge of selenium deficiency or a potentially selenium deficient. A significant positive correlation between FFQS' and hair selenium content was noted in this study, which indicates that the FFQS' established in this study is a practical tool for estimating the current selenium nutrition levels of residents in low-selenium areas. This correlation can clarify the diet pattern and roughly assess the selenium nutrition level based on the consumption frequency of various non-staple foods and the ratio of locally and imported staple foods. There is practical significance in improving the selenium nutrition level and controlling the risk of endemic diseases caused by selenium deficiency by increasing the proportion of non-local high-selenium staple foods consumed and the diversity of food types consumed for the current residents.

Author Contributions: Conceptualization, X.W. and H.L. and L.Y. and. C.K.; methodology, X.W. and H.L. and L.Y. and J.W.; software, X.W.; validation, X.W. and H.L. and L.Y.; formal analysis, X.W. and H.L.; investigation, X.W. and H.L. and C.K. and Y.L.; resources, X.W. and H.L. and L.Y.; data curation, X.W. and H.L.; writing-original draft preparation, X.W.; writing-review and editing, H.L. and L.Y. and J.W.; visualization, X.W. and H.L; supervision, H.L. and L.Y. and Y.L.; project administration, H.L.; funding acquisition, H.L. and J.W. All authors have read and agreed to the published version of the manuscript.

Funding: This research was funded by the National Key Research and Development Program of China (2019YFA0607404) and the National Natural Science Foundation of China (No. 41671500, 41907390).

Acknowledgments: We would like to thank the Center for Disease Prevention and Control of Binxian County, Shaanxi Province, for their help during the field investigations.

Conflicts of Interest: The authors declare no conflict of interest.

\section{References}

1. Rayman, M.P. The importance of selenium to human health. Lancet 2000, 356, 233-241. [CrossRef]

2. Dinh, Q.T.; Cui, Z.; Huang, J.; Tran, T.A.T.; Wang, D.; Yang, W.; Zhou, F.; Wang, M.; Yu, D.; Liang, D. Selenium distribution in the Chinese environment and its relationship with human health: A review. Environ. Int. 2018, 112, 294-309. [CrossRef] [PubMed]

3. Marek, K.; Stanisław, B. Current Knowledge on the Importance of Selenium in Food for Living Organisms: A Review. Molecules 2016, 21, 609. [CrossRef]

4. Li, N.; Gao, Z.; Luo, D.; Tang, X.; Chen, D.; Hu, Y. Selenium level in the environment and the population of Zhoukoudian area, Beijing, China. Sci. Total Environ. 2007, 381, 105-111. [CrossRef] 
5. Rayman, M.P. Food-chain selenium and human health: Emphasis on intake. Br. J. Nutr. 2008, 100, $254-268$. [CrossRef]

6. Chen, J. An original discovery: Selenium deficiency and Keshan disease (an endemic heart disease). Asia Pac. J. Clin. Nutr. 2012, 21, 320-326. [CrossRef]

7. Wu, Q.; Rayman, M.P.; Lv, H.; Schomburg, L.; Cui, B.; Gao, C.; Chen, P.; Zhuang, G.; Zhang, Z.; Peng, X.; et al. Low population selenium status is associated with increased prevalence of thyroid disease. J. Clin. Endocr. Metab. 2015, 100, 1-11. [CrossRef]

8. Kieliszek, M. Selenium-Fascinating Microelement, Properties and Sources in Food. Molecules 2019, $24,1298$. [CrossRef]

9. Li, H.R.; Yang, L.S.; Tan, J.A.; Wang, W.Y.; Hou, S.F.; Li, Y.H.; Yu, J.P.; Wei, B.G. Progress on selenium deficiency in geographical environment and its health impacts in China. Curr. Biotechnol. 2017, 7, 381-386. (In Chinese) [CrossRef]

10. Bai, G.L. Review and thinking on the prevention and treatment of selenium salt in the area of Kaschin-Beck disease in Shaanxi Province. Chin. J. Endemiol. 2013, 32, 584-585. (In Chinese) [CrossRef]

11. Li, S.; Bañuelos, G.S.; Wu, L.; Shi, W. The Changing Selenium Nutritional Status of Chinese Residents. Nutrients 2014, 6, 1103-1114. [CrossRef] [PubMed]

12. Piccinini, L.; Borella, P.; Bargellini, A.; Medici, C.I.; Zoboli, A. A case-control study on selenium, zinc, and copper in plasma and hair of subjects affected by breast and lung cancer. Biol. Trace. Elem. Res. 1996, 51, 23-30. [CrossRef] [PubMed]

13. Borella, P.; Bargellini, A.; Caselgrandi, E.; Piccinini, L. Observations on the use of plasma, hair and tissue to evaluate trace element status in cancer. J. Trace Elem. Med. Biol. 1997, 11, 162-165. [CrossRef]

14. Chen, X.; Yang, G.; Chen, J.; Chen, X.; Wen, Z.; Ge, K. Studies on the relations of selenium and keshan disease. Biol. Trace. Elem. Res. 1980, 2, 91-107. [CrossRef] [PubMed]

15. Dong, Z.; Bank, M.S.; Spengler, J.D. Assessing metal exposures in a community near a cement plant in the Northeast U.S. Int. J. Environ. Res. Public Health 2015, 19, 952-969. [CrossRef] [PubMed]

16. Ashton, K.; Hooper, L.; Harvey, L.J.; Hurst, R.; Casgrain, A.; Fairweather-Tait, S.J. Methods of assessment of selenium status in humans: A systematic review. Am. J. Clin. Nutr. 2009, 89, 2025S-2039S. [CrossRef]

17. Yang, G.; Zhou, R.; Yin, S.; Gu, L.; Yan, B.; Liu, Y.; Li, X. Studies of safe maximal daily dietary selenium intake in a seleniferous area in China. I. Selenium intake and tissue selenium levels of the inhabitants. J. Trace Elem. Electrolytes Health Dis. 1989, 3, 77-87.

18. Ortaç, E.; Ozkaya, O.; Saraymen, R.; Yıldız, N.; Bedir, A.; Buyan, N.; Bek, K.; Okuyucu, A.; Baysal, K. Low hair selenium and plasma glutathione peroxidase in children with chronic renal failure. Pediatr. Nephrol. 2006, 21, 1739-1745. [CrossRef]

19. Li, Y.P.; He, Y.N.; Zhai, F.Y.; Yang, X.G.; Hu, X.Q.; Zhao, W.H.; Ma, G.Y. Comparison of Assessment of Food Intakes by Using 3 Dietary Survey Method. Chin. J. Prev. Med. 2006, 40, 273-280. (In Chinese) [CrossRef]

20. Li, Y.P.; Song, J.; Pan, H.; Yao, M.J.; Hu, X.Q.; Ma, G.S. Accuracy of food frequency questionnaire in evaluating population energy and nutrient intake. Acta. Nutr. Sin. 2006, 28, 143-147. [CrossRef]

21. Hu, Y.F.; Chan, M.H. Factors associated with the blood and urinary selenium concentrations in the Canadian population: Results of the Canadian Health Measures Survey (2007-2011). Int. J. Hyg. Environ. Health 2018, 221, 1023-1031. [CrossRef] [PubMed]

22. Forman, J.P.; Stampfer, M.J.; Curhan, G.C. Diet and lifestyle risk factors associated with incident hypertension in women. JAMA 2009, 302, 401-411. [CrossRef] [PubMed]

23. Keshan Disease Research Group of the Chinese Academy of Medical Sciences. Observations on effect of sodium selenite in prevention of Keshan disease. Chin. Med. J. 1979, 92, 471-476. [CrossRef]

24. Tan, J.A. Environmental Selenium and Health; People's Medical Publishing House: Beijing, China, 1989.

25. Li, R.B.; Tan, J.A.; Wang, W.Y.; Zhu, W.; Yang, L.; Li, D.; Wang, L.; Miao, C.; Wang, J.; Zhang, J. Study on Increasing Selenium Flux in Food Chain to Control Kaschin-Beck Disease and Keshan Disease. Acta. Geogr. Sin. 1999, 54, 158-164. (In Chinese) [CrossRef]

26. Yang, X.D.; Dai, H.X.; Guo, X. Changes of selenium content in hair samples of people in Kaschin-Beck disease areas two months after stopping selenium salt in Shaanxi Province in 2012. Chin. J. Endemiol. 2016, 35, 361-364. (In Chinese) [CrossRef]

27. Zhang, B.; Yang, L.; Wang, W.; Li, Y.; Li, H. Environmental selenium in the Kaschin-Beck disease area, Tibetan Plateau, China. Environ. Geochem. Health 2011, 33, 495-501. [CrossRef] 
28. National Bureau of Statistics of China. China Statistics Yearbook; China Statistics Press: Beijing, China, 2018.

29. Pestitschek, M.; Sonneck-Koenne, C.; Zakavi, S.R.; Li, S.; Knoll, P.; Mirzaei, S. Selenium intake and selenium blood levels: A novel food frequency questionnaire. Wien. Klin. Wochenschr. 2013, 125, 160-164. [CrossRef]

30. Yin, D.; Li, X.Y.; Liu, Y.X.; Meng, Y.Y.; Huang, D.L.; Qiu, W.H.; Wang, Z.H. Dietary selenium nutrition levels among the residents of a typical Kaschin-Beck disease-endemic area in Wei-bei Highland, China. J. Agro-Environ. Sci. 2019, 38, 41-49. (In Chinese) [CrossRef]

31. Yang, Y.X. Chinese Food Composition Tables; standard ed.; National Institute for Nutrition and Health, Chinese Center for Disease Control and Prevention, Peking University Medical Press: Beijing, China, 2018.

32. Wu, Y.N.; Zhao, Y.F.; Li, J.G. The Fifth China Total Diet Study; Science Press: Beijing, China, 2018.

33. The Chinese Nutrition Society. The Food Guide Pagoda for Chinese Residents. Available online: http: //dg.cnsoc.org/upload/images/source/20160519163856103.jpg (accessed on 20 June 2016).

34. Wang, J.; Li, H.; Li, Y.; Yu, J.; Yang, L.; Feng, F.; Chen, Z. Speciation, distribution and bioavailability of soil selenium in the Tibetan Plateau Kashin-Beck disease area-A case study in Songpan County, Sichuan Province, China. Biol. Trace Elem. Res. 2013, 156, 367-375. [CrossRef]

35. Zhao, Z.J.; Li, Q. Analysis of hair selenium content in children with Kashin-Beck disease in Guide County, Qinghai Province before and after selenium supplementation. Chin. J. Endemiol. 2012, 31, 118. (In Chinese) [CrossRef]

36. Yang, X.D.; Dai, H.X.; Ren, Y.F.; Du, Y. Selenium content in hair samples of people in Kaschin-Beck disease areas in Shaanxi Province. Chin. J. Endemiol. 2018, 37, 330-333. (In Chinese) [CrossRef]

37. Shi, Z.; Hu, X.; Yuan, B.; Pan, X.; Dai, Y.; Holmboe-Ottesen, G. Association between dietary patterns and anaemia in adults from Jiangsu Province in Eastern China. Br. J. Nutr. 2006, 96, 906-912. [CrossRef] [PubMed]

38. Skalny, A.V.; Burtseva, T.I.; Salnikova, E.V.; Ajsuvakova, O.P.; Skalnaya, M.G.; Kirichuk, A.A.; Tinkov, A.A. Geographic variation of environmental, food, and human hair selenium content in an industrial region of Russia. Environ. Res. 2019, 171, 293-301. [CrossRef] [PubMed]

Publisher's Note: MDPI stays neutral with regard to jurisdictional claims in published maps and institutional affiliations.

(C) 2020 by the authors. Licensee MDPI, Basel, Switzerland. This article is an open access article distributed under the terms and conditions of the Creative Commons Attribution (CC BY) license (http://creativecommons.org/licenses/by/4.0/). 